\title{
Inmigración, crisis económica y discursos radiofónicos: hacia un lenguaje excluyente
}

\author{
Iolanda TORTAJADA \\ Universitat Rovira i Virgili \\ iolanda.tortajada@urv.cat \\ Dolors COMAs D’Argemir I CENDRA \\ Universitat Rovira i Virgili \\ dolors.comasdargemir@urv.cat \\ Raúl Martínez CORCUERA \\ Universitat de Vic \\ raul.martinez@uvic.cat
}

Recibido 12 de septiembre de 2013

Aceptado: 17 de marzo de 2014

\begin{abstract}
Resumen
Los medios de comunicación juegan un rol fundamental en la percepción social del proceso migratorio y de las minorías étnicas. A través del análisis de un conjunto de emisiones de Catalunya Radio, RAC1 y la COPE, el estudio que presentamos pretende determinar si el discurso radiofónico se fundamenta en un lenguaje inclusivo que contribuye a la cohesión social, o bien promueve un sobredimensionamiento de los conflictos contribuyendo a extender la xenofobia. Coincidiendo con la crisis, el lenguaje excluyente se consolida y se extiende en los medios. El análisis desarrollado evidencia el uso de conceptos y estrategias discursivas que remiten, por una parte, al racismo moderno y, por otra, al lenguaje del odio, siendo frecuentes las imprecisiones, la invisibilidad u homogeneización de determinados colectivos, la contraposición nosotros-ellos o enfoques basados en el conflicto que enfatizan las diferencias étnicas.
\end{abstract}

Palabras clave: lenguaje, discurso, inmigración, radio, inclusión

\section{Immigration, Economic Crisis, and Radio Discourse: Breeding Ground for an Excluding Kind of Language}

\begin{abstract}
The media play a pivotal role in shaping a society's view of migration processes and of the ethnic minorities brought about by such processes. By analyzing a series of broadcasts by (Catalan radio networks) Catalunya Ràdio and RAC1, and by (Spain-wide radio network) COPE, the study we introduce here purported to determine whether radio broadcast discourse in Catalonia is engendering an inclusive type of language that contributes to social unity or whether it is overstating conflict and thus helping to spread xenophobia instead. In times of economic crisis, instances of excluding language seem to gain currency and grow more widespread throughout the media. Our analysis shows how both the concepts and the discourse strategies used in these broadcasts refer us in part to hate speech and to a modern type of racism more generally, as they are rife with inaccuracies about certain groups, deny minorities of proper visibility, erase their internal differences by unduly homogenizing them, and overstress ethnic opposition by emphasizing the us vs. them antagonism and by using conflict-based approaches to deal with these topics.

Keywords: language, discourse, immigration, radio, inclusion

\section{Referencia normalizada}

TORTAJADA, Iolanda; COMAS D'ARGEMIR I CENDRA; Dolors; y MARTÍNEZ CORCUERA, Raúl (2014): "Inmigración, crisis económica y discursos radiofónicos: hacia un lenguaje excluyente". Estudios sobre el Mensaje Periodístico. Vol. 20, Núm. 2 (julio-diciembre), págs.: 899-916. Madrid, Servicio de Publicaciones de la Universidad Complutense.
\end{abstract}


Sumario: 1. Introducción. 2. El contexto sociopolítico. Discursos políticos y mediáticos sobre la inmigración. 3. Objetivos específicos y metodología. 4. Definición de la situación a partir de la sobrerrepresentación y el conflicto. 5. Formas de lenguaje excluyente; 5.1. Falta de argumentos, falacias y trampas argumentales; 5.2. Generalizaciones, invisibilidad, descalificaciones; 5.3. La contraposición nosotrosellos; 5.4. Enfoques a partir del conflicto y la hostilidad. 6. Formas de lenguaje del odio. 7. Conclusiones. 8. Referencias bibliográficas. 9. Agradecimientos.

\section{Introducción}

El objetivo de este artículo es estudiar el lenguaje utilizado en los medios de comunicación como indicador del grado de inclusión de la diversidad cultural en el mensaje comunicativo. Para ello, analizaremos los contenidos sobre inmigración y diversidad cultural que aparecen en el medio radiofónico, tomando como referencia las emisiones de Catalunya Radio, RACl y COPE. No trataremos sólo el mensaje periodístico, sino también las intervenciones de opinadores y oyentes en las tertulias y su interacción con los conductores del programa para identificar los discursos que están presentes en la realidad social y que los medios transmiten y reelaboran.

Nuestra hipótesis es que en los medios de comunicación se está produciendo una presencia progresiva de un lenguaje excluyente que, en parte, se corresponde con la existencia de prejuicios xenófobos y racistas en la sociedad y su creciente explicitación en el lenguaje político. Esta tendencia se exacerba con la crisis económica, en que se reactivan los miedos y prejuicios atávicos, acentuando los estereotipos, las amalgamas y las derivas xenófobas. En este sentido, los contenidos presentes en los medios de comunicación no son sólo un asunto mediático, sino que están fuertemente vinculados al contexto social y político.

Los medios de comunicación no sólo reflejan la realidad, también contribuyen a construirla y, por ello, es esencial analizar el lenguaje que utilizan. En la construcción de mensajes influyen cuestiones ideológicas y aspectos tales como las intenciones, el contexto, así como la propia organización mediática, las rutinas periodísticas y las fuentes utilizadas (Vliegenthart and van Zoonen, 2011). El lenguaje no es neutro y el hecho de escoger unos términos u otros hace que se generen mensajes más o menos estereotipados, más o menos excluyentes (Fernández, 2013; Martínez Lirola, 2013). Resulta útil en este sentido la perspectiva del encuadre, para indicar el proceso mediático de selección, interpretación y evaluación de algunos aspectos de la realidad percibida (Entman, 1993). Entendemos los marcos como principios organizativos que dan forma al discurso (Reese et al., 2001) y que se manifiestan en el texto a través de la inclusión o exclusión de términos específicos, imágenes estereotipadas y frases que refuerzan determinados juicios (Entman, 1993). Así pues, una primera cuestión consistirá en describir cuáles son estos conceptos clave y a qué tipo de valoración se asocian.

Además, en nuestro análisis sobre el lenguaje en la radio, mostraremos la presencia del denominado racismo moderno o simbólico, por el que el factor cultural sustituye el factor racial como explicativo de las diferencias entre las personas, con mecanismos equivalentes de clasificación y jerarquización (Barker, 1981, Stolcke, 1995, Taguieff, 1988). Robert Entman (1992) aplica esta perspectiva al análisis de los medios y operacionaliza este concepto en su estudio sobre las representaciones de la 
población negra en televisión. Constata que el racismo tradicional, basado en la creencia de la inferioridad de los negros, prácticamente ha desaparecido entre las clases medias y del discurso público, y que ha sido sustituido por el racismo moderno o simbólico. En el discurso mediático se expresa negando la existencia de discriminación racial, mostrando la mayor implicación de los negros en actos delictivos, denunciando su uso abusivo de los servicios públicos, y considerando excesivas sus reivindicaciones. Se trata de "una amalgama de sentimientos negativos (especialmente miedo y resentimiento), rechazo a las demandas de los líderes negros y negación de que el racismo todavía sea un problema" (Entman, 1992: 342). Haciendo una traslación de este enfoque a la situación actual de España podremos constatar la existencia de algunos de estos argumentos referidos a las personas inmigradas, con especial susceptibilidad respecto a las practicantes del islam.

Trataremos también de identificar la presencia o ausencia de lenguaje del odio, a partir de las estrategias aplicadas en el estudio de Noriega e Iribarren (2009) sobre las radios comerciales en Estados Unidos. El lenguaje del odio considera los inmigrados como antitéticos a los valores nucleares que se atribuyen a los autóctonos o a la nación y como una amenaza a su forma de vida. Los indicadores que utilizan Noriega e Iribarren (2009) permiten identificar si los medios utilizan un lenguaje que contribuye a crear un clima de odio y prejuicio contra determinados colectivos sociales, pero también, en contraposición, para caracterizar el lenguaje inclusivo. Justamente, una parte derivada de nuestra investigación ha servido para la elaboración de una Guía de lenguaje inclusivo (Tortajada et al., 2013) orientada a la reflexión sobre los términos utilizados en los medios y la propuesta de términos no excluyentes.

Cuando nos referimos al lenguaje de los medios, consideramos no sólo los términos utilizados y los relatos que los incluyen, sino también el contexto narrativo que les da significado. Conectar aquello que ha sido seleccionado con una narrativa que promueve una interpretación concreta forma parte del proceso de enmarcado, que se caracteriza por su naturaleza diacrónica y su resonancia cultural (Entman, 2010). Por ello, hay que considerar también el contexto de carácter social, económico, político y mediático que resignifica estos términos y los confronta con las ideas y valores que se van imponiendo como hegemónicos.

En sociedades complejas, mudables y plurales como las que vivimos se necesitan referencias compartidas. En un trabajo sobre la modernidad, el pluralismo y la crisis de sentido, Berger y Luckman afirman: "Una sociedad es absolutamente inconcebible sin valores comunes, y sin interpretaciones compartidas de la realidad". Por ello las sociedades han de mantener "reservas de sentido" (1994: 43). Los medios de comunicación hacen accesibles para todas las personas las distintas reservas de sentido, afirmando la continuidad subyacente de las cosas y generando comprensiones compartidas. En consecuencia, los medios de comunicación tienen un papel importante para la integración social porque ayudan a las personas a visualizar la sociedad, a sentirse conectadas a ella y a dar sentido a sus procesos (Comas d'Argemir, 2008). El uso de un lenguaje excluyente en términos de diversidad cultural tiene pues consecuencias reales para personas reales. Según Dyer (1993) las representaciones dependen directamente de la manera en que determinados colectivos son tratados en la vida 
y, además, delimitan y condicionan su existencia social. De ahí la importancia de identificar a través del lenguaje cómo los medios cumplen esta función social.

\section{El contexto sociopolítico. Discursos políticos y mediáticos sobre la inmigración}

Aunque ya estaba presente desde finales de los años 90, la inmigración irrumpe con fuerza en la agenda política y mediática a partir del 2009 y, en el caso de Cataluña, se expresa con mucha fuerza en el contexto de las elecciones autonómicas (noviembre de 2010) y de las elecciones municipales (mayo de 2011). Esta irrupción va acompañada de un lenguaje excluyente que muestra los componentes negativos de la inmigración y activa los miedos de los ciudadanos al asociar inmigración e inseguridad, paro o falta de recursos sociales. La inflexión coincide con el estallido de la crisis económica, que modifica el contexto político y las ideas dominantes.

El proceso de inmigración extranjera en España se caracteriza por haber sido breve en el tiempo y muy intenso, lo que en buena parte se explica por el crecimiento económico continuado que hubo hasta el año 2008, que generó una importante oferta de trabajo. Según datos del INE, la evolución demográfica en los años 2000-2013 ha tenido dos periodos distintos: por un lado, una alta intensidad de flujos migratorios hasta 2008, y, a partir de entonces, una menor entrada de población inmigrante. En 2001, las personas extranjeras en España eran 1.572.017 (el 3,85\% de la población); en 2005 eran ya 3.691 .500 (un 8,4\% del total) y en 2009 ascienden a 5.998 .691 (el 12\% de la población de hecho).

Todo parece indicar que la disminución en intensidad de la afluencia migratoria coincide con el aumento en intensidad de la crisis económica, que se ceba especialmente en la población inmigrada (Carrasco y García, 2011). Así, el 31 de marzo de 2013, la población extrajera disminuye y se reduce a 5.467 .955 personas, según datos del Observatorio Permanente de la Inmigración. Las comunidades autónomas con más presencia de extranjeros son Cataluña (con 1.253.105), Madrid (con 928.432), Andalucía y la Comunidad Valenciana (que superan los 700.000). Estas cuatro comunidades integran el 65,67\% de los extranjeros residentes en España (pese a que, entre las cuatro, representan apenas la mitad de la población española).

Dadas las circunstancias, pues, no es exagerado afirmar que la incorporación de la población extranjera ha sido bastante satisfactoria globalmente, y los episodios fuertemente conflictivos en estos años de crecimiento han sido pocos. Administraciones públicas y organizaciones ciudadanas contribuyen a generar acciones favorables a la convivencia facilitando el acceso a los servicios públicos o promoviendo programas para la integración y el conocimiento mutuo. Esto ha sido de forma desigual y con resultados variables, pero lo que queremos destacar aquí es que en este período de crecimiento se hacen esfuerzos para mantener la cohesión social y se generan múltiples plataformas de consenso.

En el año 2009 se produce una inflexión importante en el contexto político y mediático. La crisis económica afecta gravemente la situación de muchas personas, incrementa los miedos y la inseguridad y todo ello alimenta la percepción negativa de la inmigración. E1 77\% de los españoles considera "excesivo" o "elevado" el número de inmigrados, según el informe Evolución del racismo y la xenofobia en España 2009 (Cea d'Ancona y Vallés, 2009). Este informe revela aspectos concretos de las 
imágenes negativas de la inmigración, que se centran básicamente en el acaparamiento de ayudas públicas, el abuso y degradación de los servicios públicos (educación y sanidad) y las repercusiones negativas en el mercado laboral (descenso de salarios y quitar puestos de trabajo).

En este contexto, los consensos básicos en torno a la inmigración se rompen. Algunos partidos políticos utilizan la inmigración como un recurso electoral y las opciones xenófobas consiguen representación en diversos municipios catalanes. Plataforma por Catalunya, que se presenta con el lema electoral "Primero los de casa", consigue 67 concejales. El candidato del Partido Popular en Badalona utiliza el lema "Mano dura contra los que no se adaptan" y gana la alcaldía. Tan sólo cinco años atrás, este tipo de programas políticos y declaraciones (los inmigrantes no se adaptan a nuestras costumbres, nos impondrán el burca, abusan de nuestros servicios públicos, son delincuentes, son unos fanáticos religiosos) habrían sido objeto de rechazo social. Actualmente, en cambio, la gestión del prejuicio, de los miedos y del resentimiento se ha convertido en un ingrediente trivial de la confrontación política. Ha obtenido réditos electorales y se ha hecho aceptable para mucha gente a la que no calificaríamos de xenófoba o de racista (Van Dijk, 2011).

En los medios de comunicación se ha ido consolidando y extendiendo un discurso excluyente, que se abre paso entre los profesionales e invitados a debates o tertulias, como tendremos ocasión de mostrar a partir de nuestra investigación. La inmigración y las minorías étnicas o bien son ignoradas o bien aparecen representadas continuamente de forma negativa, ya sea como causantes de problemas o como personas con problemas. La polarización nosotros-ellos, la exacerbación de los problemas sociales, económicos y culturales que ellos causan y la vinculación a temas negativos como la delincuencia, el terrorismo, el desempleo o la inadaptación son estrategias discursivas frecuentes en los medios (Van Dijk, 1997). Trabajos posteriores que se han centrado en la prensa y la televisión han reforzado estos resultados mostrando que predomina el carácter negativo de la información sobre la inmigración, que los relatos acerca de ésta se vinculan a las dificultades y los problemas (Igartua y Muñiz, 2004; Retis, 2006) y que la asociación de la inmigración con la delincuencia es dominante (Igartua et al., 2006; Retis, 2006). La representación se divide entre los discursos centrados en la amenaza que suponen los emigrantes y los centrados en su condición de víctimas y desamparados, tratando de provocar la compasión (Rizo, 2001; Giró et al., 2006; Retis, 2006).

Esta tendencia representacional persiste en la actualidad. Giró y Muixí (2011: web) analizan en cinco televisiones el tratamiento informativo de tres casos de tensiones políticas y sociales relacionadas con la inmigración, todos ellos acontecidos en 2010: las restricciones al empadronamiento por el ayuntamiento de Vic (CiU), la regulación del uso del velo integral por el ayuntamiento de Lleida (PSC) y las actuaciones contra la población gitana de origen rumano de Badalona por parte del candidato a la alcaldía del Partido Popular. En su estudio identifican cuáles son los problemas más relevantes, que en algunos casos conducen a distorsiones de la realidad, a generalizaciones excesivas y a atribuciones negativizadoras de la alteridad. Su conclusión más significativa es que la escalada del conflicto constituye el enfoque dominante: 
1) en las coberturas informativas predominan las iniciativas políticas de élite, sin que se presenten las iniciativas sociales de promoción de la convivencia existentes en las tres poblaciones analizadas;

2) predomina el enfoque dicotómico "nosotros-ellos", con una construcción homogeneizadora, negativa y estereotipante de la alteridad (frente a las dimensiones positivas que se atribuyen al endogrupo);

3) la cobertura informativa pivota sobre la confrontación, los choques y conflictos, y no tanto en sus causas o en el impacto que pueden tener y, por consiguiente, se orienta hacia la victoria de una parte sobre la otra.

Esta escalada de enfoques excluyentes se añade a la insuficiencia con que los medios de comunicación reflejan la diversidad cultural. Así lo constata el informe del Consell de l'Audiovisual de Catalunya (CAC) (2009) sobre la presencia de la inmigración en la información a partir del análisis de los programas informativos emitidos entre enero y marzo del 2009 en seis televisiones. Las personas inmigradas tienen escasa visibilidad (un 2,8\% del tiempo de palabra) y frecuentemente son tratadas como problema o como víctimas. El 49,7\% de las informaciones son del ámbito policial y judicial, pero en los titulares la proporción se eleva hasta el 63,6\%. Es decir, la inmigración resulta visible cuando se asocia al conflicto. Es significativo además que las noticias que tratan específicamente sobre inmigración tengan mayoritariamente como protagonistas (un 69,3\%) a personas no inmigradas. La conclusión es que las personas inmigradas están representadas como "otros" en unas noticias que son para "nosotros".

Los estudios sobre recepción de los medios confirman la interpretación crítica que los colectivos afectados hacen sobre esta escasa presencia de personas inmigradas en los medios y de su aparición en clave conflictiva. Esta representación distorsionada es percibida como una barrera para la participación social (Retis, 2006; Tortajada, 2009).

\section{Objetivos específicos y metodología}

El objetivo específico de la investigación ha sido determinar hasta qué punto el discurso mediático se fundamenta en el lenguaje del odio y/o en el racismo moderno, o bien contribuye al reconocimiento e inclusión de las personas inmigradas y las minorías étnicas. Para ello nos hemos centrado en el análisis empírico de algunos programas radiofónicos.

Hemos elegido la radio por dos razones. Por una parte, debido a su fuerte penetración entre la audiencia. Los datos del EGM (Octubre 2012 a mayo 2013) reflejan que un $61,8 \%$ de la población en España escucha la radio diariamente, con tendencia a un incremento sostenido respecto a años anteriores (en el 2008 fue de un 53,1\%). La penetración radiofónica es especialmente elevada entre las franjas de edad comprendidas entre los 25 a 34 años (un 68,9\%) y los 35 a 44 años (un 69,9\%) y los grupos de edad más joven se sitúan por encima de la media. El segundo motivo es que, a pesar de su relevante presencia, la radio siempre ha tenido una posición secundaria en los análisis mediáticos en general y, en particular, en los estudios sobre minorías étnicas y procesos migratorios. 
Hemos analizado los magazines radiofónicos emitidos entre el 17 y el 21 de enero de 2011. Seleccionamos estas fechas porque incluían una elevada concentración de noticias y comentarios relacionados con los acontecimientos que los medios etiquetaron como 'altercados sociales' en la población de Salt (Girona), como consecuencia de que un menor de origen marroquí cayese desde una azotea huyendo de la policía. Este periodo incluyó además informaciones y comentarios vinculados a la ordenanza aprobada por el ayuntamiento de Lleida para prohibir el uso del velo integral en los espacios públicos. Escogimos una emisora pública, Catalunya Ràdio, y una privada, $R A C 1$. Los programas estudiados son El matí de Catalunya Ràdio y El món de RACl por ser los magazines con mayor audiencia en Cataluña en aquellas fechas: 640.000 oyentes diarios en el caso de $R A C 1$, y 424.000 en el de Catalunya Ràdio, según datos del EGM de junio de 2011. Como complemento, incorporamos también el programa Así son las mañanas de COPE. Escuchamos íntegramente estos programas y efectuamos la transcripción y vaciado de los contenidos relativos a inmigración y minorías étnicas, que sumaron un total de 2 horas, 2 minutos y 3 segundos en Catalunya Ràdio; 59 minutos y 34 segundos en $R A C 1$, y 14 minutos y 16 segundos en COPE. El CAC nos facilitó las grabaciones de los programas.

Combinando deducción e inferencia hemos recogido los conceptos utilizados por quienes participaron en los programas para referirse a cuestiones de inmigración y los temas y enfoques a los que estos conceptos han sido asociados. A partir de estudios previos, nos ha interesado establecer hasta qué punto las estrategias discursivas respondían al lenguaje del odio (uso de datos falsos, argumentación defectuosa, lenguaje que divide y/o metáforas deshumanizadoras) o a un lenguaje vinculado con el racismo moderno (hostilidad, resistencia a las aspiraciones políticas de las minorías y/o negación de que la discriminación siga siendo un problema para las minorías). Al mismo tiempo, nos ha interesado observar el lenguaje que, en vez de excluir, incorpora estrategias inclusivas como: usar datos contrastados, argumentación basada en evidencias, lenguaje que no busca ni la división ni el conflicto, evitar la cosificación e instrumentalización de los inmigrantes y las minorías, explicar las aspiraciones políticas de inmigrantes y minorías, no negar la discriminación y ponerla de manifiesto, y seguir las recomendaciones para el tratamiento informativo de la inmigración. La inferencia también nos ha servido para detectar otros aspectos que emergen de la propia evolución del discurso mediático y social sobre la inmigración.

\section{Definición de la situación a partir de la sobrerrepresentación y el conflicto}

En los días analizados predomina la noticia y los comentarios de los hechos acontecidos en Salt a raíz de la muerte de un menor cuando era perseguido por la policía. Esto provocó una reacción airada por parte de algunos jóvenes de origen marroquí, con episodios violentos en la calle, quema de coches y de contenedores, confrontaciones entre vecinos, y se estaba preparando una manifestación en favor de la convivencia con el lema "Queremos vivir en Salt en paz y bien". La atención informativa se centró también, aunque en menor medida, en la suspensión cautelar de la ordenanza que prohibía el uso del velo integral en los edificios públicos de Lleida. Se trataron también otros temas, pero con una presencia muy poco relevante: embarazos no deseados en 
menores, políticas de inmigración, referencias diversas a personas inmigradas, etc. En el cuadro siguiente podemos apreciar el tiempo que se dedica a cada uno de estos temas.

\begin{tabular}{|c|c|c|c|c|c|c|c|c|c|}
\hline \multirow{2}{*}{ Fecha } & \multicolumn{3}{|c|}{ El Matí. Catalunya Ràdio } & \multicolumn{3}{|c|}{ El Món. $R A C l$} & \multicolumn{3}{|c|}{ Así son las mañanas. $C O P E$} \\
\hline & Salt & Burca & Otras & Salt & Burca & Otras & Salt & Burca & Otras \\
\hline 17-01-2011 & $00: 16: 31$ & 00:00:10 & $00: 00: 11$ & $00: 02: 54$ & 00:00:00 & $00: 04: 14$ & 00:00:00 & 00:00:00 & $00: 00: 40$ \\
\hline 18-01-2011 & $00: 00: 24$ & $00: 01: 00$ & $00: 03: 14$ & $00: 33: 40$ & $00: 04: 47$ & $00: 05: 00$ & $00: 00: 00$ & $00: 00: 23$ & $00: 00: 40$ \\
\hline 19-01-2011 & $01: 37: 37$ & 00:00:00 & 00:00:00 & 00:00:00 & 00:00:00 & $00: 00: 16$ & 00:00:00 & 00:00:00 & 00:00:00 \\
\hline 20-01-2011 & 00:00:04 & 00:00:00 & $00: 00: 16$ & $00: 00: 00$ & 00:00:00 & $00: 01: 17$ & 00:00:00 & 00:00:00 & $00: 06: 30$ \\
\hline 21-01-2011 & $00: 00: 00$ & $00: 02: 16$ & $00: 00: 20$ & $00: 05: 21$ & $00: 00: 00$ & $00: 02: 05$ & $00: 00: 00$ & $00: 04: 43$ & $00: 01: 20$ \\
\hline Totales & 01:55:16 & 00:03:26 & 00:03:52 & 00:41:55 & 00:04:47 & 00:12:52 & 00:00:00 & 00:05:06 & 00:09:10 \\
\hline TOTAL & & 02:02:34 & & & 00:59:34 & & & 00:14:16 & \\
\hline
\end{tabular}

Cuadro 1. Tiempo de noticia de cada programa por temas

La primera constatación es el sobredimensionamiento mediático de los acontecimientos de Salt. A menudo, se asimilan a los incidentes de las banlieues de París del año 2005 o a Harlem y sus niveles de peligrosidad, construyendo un imaginario social en que la inmigración aparece como fuente de problemas, delincuencia, violencia o fanatismo. Si se comparan los hechos acontecidos en Salt con otros similares en poblaciones vecinas, estas correlaciones no se sostienen. En Salt se quemaron coches, 25 en total, pero resulta que en la provincia de Girona, en el transcurso de un año, se quemaron 578 coches: 93 de ellos en Figueres y 66 en la ciudad de Girona (Navales, 2011). Mientras los incidentes de otros lugares pasaron desapercibidos, lo sucedido en Salt ha tenido tanta atención mediática que el municipio aparece hoy asociado al conflicto y a la confrontación social atribuidos a diferencias culturales. Deviene así el símbolo y modelo de un conflicto étnicoreligioso, utilizado políticamente y amplificado por los medios.

La segunda noticia destacada en los días analizados se refiere a la prohibición del velo integral en los espacios públicos. No se trata de la elaboración y aprobación de la ordenanza por parte del ayuntamiento de Lleida, sino de la suspensión cautelar de esta ordenanza por el Tribunal Superior de Justicia de Cataluña. El gran despliegue informativo y debate mediático que tuvo esta iniciativa política contrasta con la baja incidencia del uso del burca y del nicab en España y también en Lleida, y aunque no se dispone de cifras concretas, sí se tiene constancia que este hecho no ha provocado incidentes que hayan perjudicado la convivencia ciudadana. En todo caso esta iniciativa política y su repercusión mediática han generado un debate social en que se produce una amalgama del burca y el nicab con el islam, con el integrismo y con estereotipos negativos que se extienden a toda la comunidad musulmana.

El contexto mediático en que se sitúan estos acontecimientos se caracteriza por el predominio de un lenguaje excluyente. No son sólo las expresiones concretas utilizadas, sino la narrativa dominante, de manera que las intervenciones que utilizan un lenguaje inclusivo quedan absorbidas por este contexto excluyente. Esta situación se percibe nítidamente en el programa especial que organiza Catalunya Ràdio el 19 de enero de 2011, que se emite en directo desde Salt. Tiene una duración de 1 hora y 37 minutos, y tanto su carácter monográfico como la multiplicidad de intervenciones permiten un análisis en profundidad. En él participan tertulianos, políticos, técnicos, re- 
presentantes de entidades, personas implicadas en los incidentes, vecinos y oyentes. Algunos consideran la inmigración como una fuente de problemas y lamentan su importante presencia en el país, mientras que otros intentan contextualizarla a partir de claves económicas y sociales. La intención del programa es analizar los hechos y entenderlos. El resultado, seguramente no buscado, es que se pone el acento en el conflicto; en las diferencias culturales; en las dificultades de integración de los inmigrantes, especialmente si son musulmanes; o en la inseguridad del espacio público, en la pobreza y la delincuencia. También se responsabiliza a las administraciones públicas y a la justicia, por considerar que han propiciado la inmigración, dan demasiadas prerrogativas a las personas inmigradas, son indulgentes ante sus costumbres o tienen poca eficacia para combatir la delincuencia. Los componentes emotivos y los recursos sensacionalistas están muy presentes. En este contexto, las intervenciones razonadas que utilizan un lenguaje inclusivo aparecen como posturas a la defensiva, a contracorriente, ya que constantemente han de confrontarse con los relatos excluyentes y han de insistir en la negación de los tópicos y estereotipos atribuidos a las personas inmigradas, así como en los factores sociales que influyen en los problemas acontecidos.

\section{Formas de lenguaje excluyente}

Las formas de lenguaje excluyente detectadas en el análisis del discurso se concretan en estrategias diversas: la falta de argumentos, falacias y trampas argumentales; las generalizaciones y homogeneización de determinados colectivos; la contraposición nosotros-ellos y los enfoques a partir del conflicto-hostilidad. Expondremos brevemente en qué consisten, acompañándolo con ejemplos.

\subsection{Falta de argumentos, falacias y trampas argumentales}

Principalmente, la argumentación defectuosa detectada se debe a dos cuestiones. Por una parte, la imprecisión y simplificación de las informaciones ofrecidas; y, por otra, el uso del concepto "buenista" para oponerse a las medidas activas a favor de la igualdad étnica y la corrección política (Van Dijk, 1997) e, indirectamente, para rechazar las aspiraciones políticas de los inmigrantes (Entman, 1992).

- La acusación de "buenismo" se identifica con el lenguaje políticamente correcto. Esta estrategia discursiva busca, sin necesidad de argumentaciones, desactivar discursos y descalificar acciones y opiniones consideradas progresistas. Como cuando, por ejemplo, un tertuliano contrapone la corrección política a la posibilidad de analizar problemas y ofrecer soluciones para, después, equiparar dicha corrección con la imposibilidad de expresar que la inmigración es excesiva y que causa problemas de convivencia (Catalunya Ràdio, 19/1/2011).

- Las imprecisiones se producen por el uso abusivo de datos que no tienen contrastación estadística, por errores en el uso de los términos o por simplificaciones excesivas. Como ejemplos, un tertuliano utiliza apreciaciones subjetivas para decir que "hay demasiada inmigración" o que la "inmigración es desbordada" (Catalunya Ràdio, 19/1/2011), o una tertuliana afirma que "tenemos un problema con el islam" y que "Salt es el epicentro del salafismo en Europa" 
( $R A C 1,17 / 01 / 11)$, lo que podemos relacionar con la percepción de la inmigración como invasión o como amenaza (Van Dijk, 1997).

Un ejemplo de error en los términos sería el uso que hace el conductor del programa de "velo islámico" en vez de "velo integral" (Catalunya Ràdio, 18/1/11). Esta inexactitud favorece la imagen negativa de todas las formas de cubrir la cabeza, diluye las diversidades entre los musulmanes e ignora que el velo se utiliza también en países católicos.

\subsection{Generalizaciones, invisibilidad, descalificaciones}

Cuando a partir de un caso único se efectúa una extrapolación de una acción o conducta y se aplica a toda la población de un país, o a todo un grupo étnico, se hace una generalización que, si además es descalificadora, tiene consecuencias discriminatorias. Es el mecanismo por el que se construyen estereotipos, categorías por las que las personas inmigradas devienen una abstracción, un colectivo homogéneo fácilmente catalogable en el que se diluyen sus diversidades internas. Este aspecto tiene varias formas de concretarse:

- Expresiones deshumanizadoras. El uso de metáforas es muy recurrente cuando se habla del hecho migratorio y de las personas inmigradas. Estas metáforas simplifican y se generan desde paralelismos inexactos. Periodísticamente se utilizan a menudo y por su reiteración se convierten en un cliché.

"Mira, hemos recibido un alud de población foránea, muy foránea, es decir, de origen muy exótico para nosotros y, además, muy diferentes entre sí, y hemos sabido tratar este reto y la sangre no ha llegado al río" (Catalunya Ràdio, 19/1/11, tertuliano). En este caso, el uso del concepto "exótico" asociado al "origen muy exótico para nosotros" y el énfasis en la diferencia y en lo extraño contribuyen a la deshumanización (Noriega e Iribarren, 2009). Se asocia además a la idea del alud, como algo imparable y conectado con la invasión, incidiendo en otra estrategia discursiva común como es la autorepresentación positiva y la idea de que nosotros somos buenos con ellos (Van Dijk, 1997).

- Invisibilidad de la diversidad étnica. A menudo se utilizan etiquetas que convierten en homogéneas poblaciones que son diversas, o no se menciona la procedencia de las personas implicadas en las informaciones o comentarios.

"Estamos hablando del $40 \%$ de la población de origen inmigrante [...] la mayor parte de niños, jóvenes y familias jóvenes de Salt son de origen inmigrante" (Catalunya Ràdio, 19/1/11, tertuliano). La generalización es tan exagerada que la inmigración se confunde con un origen o procedencia.

Aparece con frecuencia el uso de términos como árabe, asiático, subsahariano, europeos del este o latinoamericano como categorías macroétnicas que presuponen la homogeneidad de grupos muy diversos y que, por su reiteración en los discursos mediáticos, se adoptan socialmente como categorías naturales.

- Lenguaje acosador. Determinadas expresiones entran en el terreno del asedio, resultando insultantes y denigrantes. Un ejemplo se observa al hablar de "so- 
ciedades atrasadas" (COPE, 21/1/11, tertuliano). En el apartado 5 trataremos más ampliamente esta dimensión, en la medida que se inscribe plenamente en el lenguaje del odio.

\subsection{La contraposición nosotros/ellos}

El enfoque a través de la contraposición nosotros/ellos construye el discurso ubicando las personas en dos bandos. Términos como autóctonos/inmigrantes, los de aquí/los de fuera, o expresiones como "catalanes de toda la vida" establecen dos grupos diferenciados. Este discurso enfatiza las diferencias y en ocasiones, incide en la dificultad o imposibilidad de comprensión mutua, y abusa de los estereotipos para justificar o legitimar esta dicotomía. Son conceptos esencialistas y asumen la inmigración como condición de la identidad e, incluso, como el factor único que define una persona. Esta estrategia discursiva de polarización tiene diversas formas de concretarse:

- Énfasis en las diferencias étnicas. Como por ejemplo cuando, sin que sea necesario para la exposición y contextualización de los hechos, se menciona el origen étnico. "Unos 50 jóvenes de origen magrebí, también amigos del herido" (Catalunya Ràdio, 17/1/11, conductor del programa).

- El uso del concepto "inmigración" de forma esencialista se produce cuando la inmigración constituye la manera principal de definir a las personas y grupos, al hablar, por ejemplo de "inmigrantes y autóctonos" (Catalunya Ràdio, 17/1/11, oyente), y cuando se establecen causalidades mal formuladas o irrelevantes: "En estos altercados, el fenómeno de la inmigración no sólo es secundario, sino inexistente" ( $R A C 1,18 / 1 / 11$, conductor del programa). En este caso, la inmigración se presenta como un factor explicativo, aunque sea por contraposición de lo que se supone que sucede normalmente.

- Estereotipos. Por un lado, tenemos el uso de los estereotipos étnicos como potentes mecanismos de enmarcamiento (Correa, 2010): es la tendencia a definir mediante etiquetas, como "velo islámico integral", "asociación islámica" o "inmigrante", que no son términos precisos y que tienden al estereotipo. Y, por otro lado, se produce un etiquetaje asociando términos negativos y conflictivos al concepto de inmigración: "Jóvenes inmigrantes, delincuentes, perseguidos por la policía, que se estrellan contra una pared, que se matan o quedan malheridos" (Catalunya Ràdio, 19/1/11, tertuliano).

- Hemos encontrado numerosas expresiones que contraponen el endogrupo con las personas inmigradas, fomentando así un lenguaje que divide. Son discursos que refuerzan, en primer lugar, un concepto esencialista de la inmigración y transmiten la idea de que estas personas no forman parte del grupo propio y, en segundo lugar, la idea de que somos "nosotros" los que hacemos un "esfuerzo de acogida". Pueden resaltarse diversos ejemplos: "Entidades inmigrantes y del pueblo" (Catalunya Ràdio, 19/1/11, periodista); "Catalanes de toda la vida" (Catalunya Ràdio, 19/1/11, oyente); "Los catalanes somos extraordinarios, supimos integrar la inmigración andaluza" (Catalunya Ràdio, 19/1/11, tertuliano); "Esta tierra es así, y esta tierra les ha dado la bienvenida con los brazos abiertos" (Catalunya Ràdio, 19/1/11, político). 


\subsection{Enfoques a partir del conflicto y la hostilidad}

En los discursos mediáticos, se produce una tendencia generalizada a resaltar el carácter conflictivo de la presencia de inmigración y a subestimar el capital social al que contribuyen (Retis, 2006). El enfoque asociado al conflicto y la hostilidad tiende a centrarse en la confrontación y a explicarla por las características culturales de los grupos en disputa. Tanto es así que, en numerosas ocasiones, no se analiza la causa del conflicto porque se da por sobreentendida (Giró y Muixí, 2011). "Si esto queda impune, los incívicos, los vándalos, los delincuentes habrán ganado la guerra, la batalla" (Catalunya Ràdio, 17/1/11, político). Hemos constatado en nuestro análisis que la inmigración se asocia a pobreza, mafia, disturbio y guerra, pero la asociación de inmigración y delincuencia es dominante (Igartua et al., 2006; Retis, 2006; Rodríguez Breijo, 2012). Las estrategias utilizadas son el énfasis en el conflicto y su etnificación.

- El énfasis en el conflicto provoca una polarización o una dramatización que oculta otros procesos políticos y sociales que intervienen en los problemas: "Recordad que en Francia esto, hace un par de años, duró meses y hubo decenas de miles de coches quemados, intervenciones policiales como si fuera la guerra" (Catalunya Ràdio, 19/1/11, tertuliano). La dramatización es evidente. La asociación reiterada de inmigración, conflictos y problemas sociales es por sí misma una fuente de conflictos.

- La etnificación del conflicto se produce cuando no se analizan las causas de un conflicto, sino que se atribuyen a las características de un determinado grupo. Así, la diferencia cultural pasa a ser entendida como algo inapelable y como fuente intrínseca de problemas. Se establece una relación de causa-efecto entre el conflicto y el origen cultural. Un participante en el programa dice, por ejemplo: "el diálogo es muy difícil a menudo, porque por su parte plantean un tema en términos religiosos y nosotros lo planteamos en términos de igualdad hombre-mujer. Y creo que se aborda desde prismas diferentes" ( $R A C 1,18 / 1 / 11$, político). Otro va más allá en esta etnificación del conflicto: "En Salt hay una célula islamista peligrosa de todo el mundo, peligrosa para todo el mundo. Y eso se ha reconocido en los medios y hoy no se ha hablado de esto" (Catalunya Ràdio, 19/1/11, oyente)

Los diversos ejemplos que hemos tratado en este apartado muestran una elevada presencia de lenguaje excluyente, aunque el corpus del discurso mediático no es homogéneo. Aparece más bien un discurso ambivalente, a veces paternalista, repleto de prejuicios, estereotipos e inexactitudes. Hemos observado la presencia de un doble lenguaje tanto entre los conductores del programa como en algunos tertulianos, que intentan entender la situación de las personas inmigradas, pero también el rechazo que generan. Comprensión pero también separación. Los marcadores nosotros/ellos aparecen de forma constante y a veces muy explícitos. Sólo hemos detectado lenguaje del odio explícito en una de las tertulias analizadas, y que es interesante presentar a partir de sus características. 


\section{Formas de lenguaje del odio}

Consideramos que hay lenguaje del odio cuando confluyen todos y cada uno de los rasgos que caracterizan el lenguaje excluyente, sin paliativos y en su mayor radicalidad. Tal como señalan Noriega e Iribarren (2009) se fundamenta en aseveraciones negativas que crean un clima de odio y prejuicio. Se trata de un uso sistemático y extensivo de hechos falsos, argumentaciones defectuosas o inexactas, lenguaje divisorio y metáforas deshumanizadoras que se dirigen hacia un grupo vulnerable. Los grupos vulnerables se consideran la antítesis de los valores nucleares atribuidos al endogrupo, y las instituciones se consideran cómplices de estos grupos. Todos estos atributos los hemos podido identificar en una parte del magazín de COPE Así son las mañanas emitido el 21 de enero de 2011. Reproducimos los fragmentos más sustantivos para analizarlos y mostrar cómo se concreta el lenguaje del odio.

Un tertuliano, refiriéndose al uso del burca, critica la postura adoptada por la Defensora del Pueblo que se opone a su prohibición si la mujer que lo lleva lo hace libremente. Este tertuliano hace las siguientes afirmaciones:

"Se trata de hábitos fracasados que van en contra de la dignidad de la mujer, en contra de la libertad de todos los individuos. Esta cultura fracasada que ha llevado a unas sociedades fracasadas en estados fracasados que hacen emigrar a la gente, que no intenten imponerla en los estados que han tenido éxito y a los cuales van los ciudadanos a vivir y a ganarse el pan; aquéllos que huyen de las sociedades fracasadas [...] Que las sociedades de éxito importen las soluciones de las sociedades fracasadas realmente parece un absurdo".

Dicen 'yo lo uso libremente porque, si no, no puedo volver a casa', ¿no? (ríe). Es la ideología dominante, sobre todo de este gobierno de cesión. Es un pensamiento débil, y lo arreglaríamos si añadimos un título al cargo de Defensora, y a partir de ahora es la Defensora del Pueblo Islámico" [...] "Si realmente eres tan creyente en la imposición del burca por parte directamente de Alá, te vas a vivir a un sitio donde se pueda vivir con burca, que no es aquí".

Las intervenciones de este tertuliano tienen un marcado carácter xenófobo, con elementos de racismo e islamofobia. Considera inferiores las sociedades que practican el islam y lo expresa con el uso reiterado del concepto "sociedades fracasadas". Incorpora también mecanismos de exclusión, conminando a marchar de España a quienes quieran vestir el burca. Los sujetos diana son las mujeres que visten burca y por extensión todos los pueblos que practican el islam. Considera cómplices de la situación tanto al gobierno español como a la Defensora del Pueblo. Se acusa al primero de hacer cesiones y de "pensamiento débil". A la Defensora se la considera demasiado tolerante y comprensiva. El lenguaje del odio se concreta en todas sus expresiones:

- Hechos falsos. Se considera que el uso del burca es una obligación religiosa del islam que impone el propio Alá. No se contextualiza en qué países y en qué circunstancias se impone el uso de esta prenda. Al descontextualizar el problema, se extiende a todas las sociedades practicantes del islam y se legitima el rechazo a esta práctica concreta y de forma más genérica a la religión que supuestamente la causa.

- Argumentaciones erróneas o defectuosas. Son las más abundantes y tienen distintas expresiones: 
- Amalgama: se identifica el burca con todo el islam. Y se culpa esta religión de atentar contra la dignidad de las mujeres.

- Inexactitudes: no identifica que el uso del burca es anterior a la existencia del islam, y que es fruto de un sistema patriarcal que utiliza la religión como legitimación.

- Implícitos, premisas ocultas: se presenta el islam como una religión rígida que impone normas injustas y opresoras. Los musulmanes causan problemas a nuestra sociedad.

- Apelación engañosa al miedo: nuestra sociedad está incorporando supuestamente las opciones de "sociedades fracasadas"

- Ataques a la persona. La Defensora del Pueblo es criticada en la médula de su función al considerar que no defiende a todos los españoles y por ello la denominan despectivamente "Defensora del Pueblo Islámico".

- Ignorancia, mala fe u olvido de la historia. Si emigrar es fruto de una "sociedad fracasada" podría aplicarse lo mismo a los más de tres millones de españoles de "cultura católica" que en el siglo XX emigraron hacia otros países, o los miles de españoles que emigran actualmente.

- Lenguaje divisorio. El contraste nosotros/ellos está muy marcado. El "nosotros" se considera incompatible con "ellos", es decir, las mujeres que llevan burca, los hombres que imponen su uso y los musulmanes en general. La superioridad del endogrupo se expresa como punto de referencia, en tanto que las sociedades que practican el islam se inferiorizan.

- Metáforas deshumanizadoras. Se presenta la presencia de mujeres con burca como una especie de catástrofe cultural, ya que consideran que acabarán imponiendo su propia lógica y costumbres a nuestra sociedad.

\section{Conclusiones}

El análisis del discurso sobre la inmigración de los magazines radiofónicos se caracteriza, en primer lugar, por una sobrerrepresentación de las situaciones que se definen como conflictivas y en las que las personas inmigradas se ven implicadas. Ya sea por conflictos sociales o culturales, el sobredimensionamiento mediático contribuye a percibir la inmigración como centro de todos los miedos y peligros sociales: desde la opresión y la falta de libertades hasta la violencia, la pobreza, las drogas y el fanatismo religioso, con una amalgama de todos estos elementos, sin hacer distinciones entre ellos.

Una segunda cuestión que pone en evidencia la investigación llevada a cabo, y que confirma la hipótesis de partida, es que, en los medios en general, y en los espacios radiofónicos analizados en particular, el lenguaje excluyente se consolida y se extiende. Al mismo tiempo, se confirma que las intervenciones que utilizan un lenguaje inclusivo, que son muy escasas, quedan absorbidas por el predominio de un contexto mediático excluyente. Así pues, el debate se produce según ejes ya establecidos en los que, principalmente, se intenta romper el binomio inmigración-delincuencia.

Las estrategias discursivas predominantes consisten en ataques a la corrección política, el uso de apreciaciones subjetivas para argumentar y el recurso a generaliza- 
ciones. Además, la diversidad étnica se invisibiliza a través de grandes etiquetas para referirse a la procedencia de las personas. Se utilizan también expresiones deshumanizadoras que enfatizan la diferencia y lo extraño, cosificando o descalificando a las personas de las que se habla, cuya identidad queda reducida a su condición de inmigrantes lo que, por añadidura, las sitúa en condición de inferioridad.

La contraposición nosotros-ellos y el énfasis en el conflicto enmarcan el uso de los conceptos. La estrategia de polarización entre nosotros y ellos se manifiesta a través del énfasis en las diferencias étnicas, la esencialización de la condición de inmigrante, el etiquetaje basado en la concatenación de estereotipos y el uso de un lenguaje que divide. Las personas inmigrantes aparecen asociadas a delincuencia y problemas. Por el contrario, los denominados autóctonos o 'de toda la vida', se presentan sufriendo las consecuencias de la desintegración social y quienes están haciendo el esfuerzo de acogida. El conflicto se explica por motivos culturales, lo que refuerza la división y fomenta la exclusión.

Los medios de comunicación inciden decisivamente en la percepción social de la inmigración y de las minorías étnicas. El uso exclusivo de estereotipos e imágenes negativas, contribuyen a extender la xenofobia. Si, por el contrario, incorporan la diversidad cultural como algo normalizado y utilizan un lenguaje inclusivo, hacen una gran contribución a la cohesión social y a evitar las fragmentaciones de la sociedad por razón de origen. Si bien los medios no crean determinadas situaciones sociales o actuaciones políticas que, lógicamente, han de reflejar, su responsabilidad es dimensionarlas y contextualizarlas, reflejar la normalidad más que la anécdota, la convivencia más que el conflicto, los discursos plurales e inclusivos más que los que estimulan la xenofobia. La normalización de la diversidad cultural es fundamental para la cohesión social y el uso de un lenguaje inclusivo constituye una pieza fundamental para este objetivo.

\section{Referencias bibliográficas}

BARKER, Martin (1981): The New Racism, London, Junction Books.

BERGER, Peter L. y LUCKMANN, Thomas (1968): La construcción social de la realidad, Buenos Aires, Amorrortu editores.

CARRASCO CARPIO, Concepción y GARCÍA SERRANO, Carlos (2011): "Inmigración y mercado de trabajo". Informe 201. Madrid, Observatorio Permanente de la Inmigración, Ministerio de Empleo y Seguridad Social. En:

http://extranjeros.empleo.gob.es/es/ObservatorioPermanenteInmigracion/Publicaciones/archivos/OPI_28_Inmigracion_y_Mercado_de_trabajo-Informe2011.pdf [fecha de consulta: 15 de agosto de 2013].

CEA D’ANCONA, M. Ángeles y VALLES MARTÍNEZ, Miguel S. (2009): Evolución del racismo y la xenofobia en España [Informe 2009]. Madrid. Ministerio de Trabajo e Inmigración. En: http://www.oberaxe.es/files/datos/4b26574eb2f66/Informe2009.pdf [fecha de consulta: 7 de febrero de 2013]

COMAS D'ARGEMIR, Dolors (2008), “Construyendo imaginarios, identidades, comunidades: el papel de los medios de comunicación”, en BULLEN, Margaret y 
DÍEZ MINTEGUI, Carmen, Retos teóricos y nuevas prácticas. San Sebastián, Ankulegi, pp. 179-208.

CONSELL DE L'AUDIOVISUAL DE CATALUNYA (2009): Valoració del Consell de l'Audiovisual de Catalunya sobre la presència de la immigració en la informació. Gener-març 2009. En: http://www.cac.cat/pfw_files/cma/actuacions/Continguts/Valoraci_informe_Immigraci_101209.pdf [fecha de consulta: 7 de febrero de 2013]

CORREA, Teresa (2010): "Framing Latinas: Hispanic women through the lenses of Spanish-language and English-language news media". Journalism, 11 (4), pp. 425443.

DYER, Richard (1993): The Matter of Images: Essays on Representation. Londres, Routledge.

ENTMAN, Robert M. (1992): "Blacks in the News: Television, Modern Racism and Cultural Change", Journalism Quaterly, 69, pp. 341-361.

ENTMAN, Robert M. (1993): "Framing: Toward clarification of a fractured paradigm", Journal of Communication, 43(4), pp. 51-8.

ENTMAN, Robert M. (2010): "Media framing biases and political power: Explaining slant in news of Campaign 2008", Journalism, 11 (4), pp. 389-408.

FERNÁNDEZ FERNÁNDEZ, Maximiliano (2013): La diversidad y la discriminación en encuadres de "El País", "El Mundo" y "ABC". Estudios sobre el Mensaje Periodístico, vol 19, Madrid, Servicio de Publicaciones de la Universidad Complutense, pp. 91-106.

GIRÓ MARTÍ, Xavier; MUIXÍ CASALDÀLIGA, Marta (2011): Cobertura televisiva de propostes politiques sobre immigració. Anàlisi de tres casos: restriccions a l'empadronament a Vic, regulació sobre l'ús del vel integral a Lleida i tensions veïnals a Badalona. Barcelona, Mesa per la Diversitat en l'Audiovisual. En: http://www.mesadiversitat.cat/materials_mesa/ [fecha de consulta: 15 de agosto de 2013]

IGARTUA, Juan José y MUÑIZ, Carlos (2004): "Encuadres noticiosos e inmigración. Un análisis de contenido de la prensa y televisión españolas". Zer. Revista de Estudios de Comunicación, 16, pp. 87-104.

IGARTUA, Juan José; MUÑIZ, Carlos; y OTERO, José Antonio (2006): "El tratamiento informativo de la inmigración en la prensa y la televisión española. Una aproximación empírica desde la teoría del Framing". Global Media Journal, 3 (5) En: http://gmje.mty.itesm.mx/igartua_muniz_otero.htm [fecha de consulta: 28 de agosto de 2013]

MARTÍNEZ LIROLA, María (2013): "Estudio de la construcción discursiva de las mujeres y los menores inmigrantes en una muestra de noticias de radio". Tonos Digital, 25 (julio de 2013). En: http://www.tonosdigital.es/ojs/index.php/tonos/article/view/995 [fecha de consulta: 17 de julio de 2013] 
NAVALES, Carlos (2011): “La inmigración y la prensa. ¡Burbujas étnicas, no!”. La Factoría, 26 de enero de 2011.

NORIEGA, Chon A. e IRIBARREN, Javier (2009): "Hate Speech on Commercial Talk Radio. Preliminay Report on a Pilot Study". Latino Policy \& Issues Brief, UCLA, 22: http://www.chicano.ucla.edu/press/briefs/documents/PB22_000.pdf>

OBSERVATORIO PERMANENTE DE LA INMIGRACIÓN (2013): Extranjeros residentes en España. A 31 de marzo de 2013. Principales resultados. Madrid, Ministerio de Empleo y de la Seguridad Social. En: http:// extranjeros.empleo.gob.es/es/Estadisticas/operaciones/con-certificado/201303/Residentes_Principales_Resultados_31032013.pdf [fecha de consulta: 15 de agosto de 2013]

REESE Stephen D., GANDY Oscar H., and GRANT August E. (eds., 2001): Framing Public Life: Perspectives on Media and Our Understanding of the Social World. Mahwah, NJ, Lawrence Erlbaum.

RETIS, Jéssica (2006). "La construcción social de la inmigración latinoamericana. Discursos, imágenes y realidades" Amérique Latine Histoire et Mémoire. Les Cahiers ALHIM, 12. En: http://alhim.revues.org/1352 [fecha de consulta: 28 de agosto de 2013]

RIZO, Marta (2001): "Miedo y compasión: dos estrategias de movilización afectiva en el discurso informativo sobre el inmigrante", Revista Comunica, 2, marzo.

RODRÍGUEZ BREIJO, Vanessa (2012): "Futbolistas o delincuentes: polarización de la imagen televisiva de los inmigrantes en el género informativo". Estudios sobre el mensaje periodístico, vol. 18, núm. 2. Madrid, Servicio de Publicaciones de la Universidad Complutense, pp. 595-612.

STOLCKE, Verena (1995): "Talking Culture: New Boundaries, New Rhetorics of Exclusion in Europe". Current Anthropology 36 (1), pp.1-23

TAGUIEFF, Pierre-André (1988): La forcé du préjugé. Essai sur le racisme et ses doubles. Paris, La Découverte.

TORTAJADA, Iolanda (2009): “¿Qué hay de nuestro aquí? Cómo se perciben en los medios algunas minorías residentes en Cataluña”, Zer, 14 (26), pp. 59-80.

TORTAJADA, Iolanda; COMAS D'ARGEMIR, Dolors; MUIXÍ, Marta; MARTÍNEZ CORCUERA, Raúl; GUARRO, Beatriu (2013): Guia de llenguatge inclusiu. Barcelona, Mesa per la Diversitat en l'Audiovisual. En: http://www.mesadiversitat.cat/materials_mesa/ [fecha de consulta: 15 de agosto de 2013

VAN DIJK, Teun A. (1997): Racismo y análisis crítico de los medios. Barcelona, Paidós.

VAN DIJK; Teun A. (2011): "Racismo, discurso y política", Dossiers. Portal de la Comunicación InCom-UAB. En: http://www.portalcomunicacion.com/monograficos_det.asp?id=179 [fecha de consulta: 7 de febrero de 2013] 
VLIEGENTHART, Rens and Liesbet VAN ZOONEN, Liesbet (2011): "Power to the Frame: Bringing Sociology Back to Frame Analysis". European Journal of Communication 26 (2), pp. 101-15.

\section{Agradecimientos}

El estudio que se presenta en este artículo forma parte de un proyecto sobre lenguaje inclusivo desarrollado por una de las comisiones de trabajo de la Mesa por la Diversidad en el Audiovisual del Consejo del Audiovisual de Catalunya. El equipo de dicha comisión está compuesto por Dolors Comas d'Argemir, Iolanda Tortajada, Marta Muixí, Raúl Martínez, Beatriu Guarro, Carme Figueras, Carme Rincón, Blanca Garcés, Lena de Botton, Leticia Hernando, Laura López, Noura Aharchi, Sebastià Porras y Salwa El Gharbi. 